\title{
Multiwalled Carbon Nanotubes Reinforced Polypropylene Composite Material
}

\author{
Juan Li \\ School of Mechanical Engineering, Nanjing Vocational Institute of Industry Technology, Nanjing 210023, China \\ Correspondence should be addressed to Juan Li; lijuan@niit.edu.cn
}

Received 14 December 2016; Revised 8 April 2017; Accepted 10 April 2017; Published 21 May 2017

Academic Editor: Andrew R. Barron

Copyright (C) 2017 Juan Li. This is an open access article distributed under the Creative Commons Attribution License, which permits unrestricted use, distribution, and reproduction in any medium, provided the original work is properly cited.

Polypropylene (PP) composites reinforced with multiwalled carbon nanotubes (MWNTs) were prepared by using twin screw extruder. The experimental results showed that with the increasing amount of MWNTs the elongation at break decreased whereas the tensile strength, bending strength, and impact strength increased. By using scanning electron microscope (SEM), we find that the hydroxyl-modified carbon nanotube has better dispersion performance in PP and better mechanical properties.

\section{Introduction}

$\mathrm{PP}$ is one of the fastest growing varieties in the world plastics industry. PP is mainly used as packaging materials, including film and plate which occupies a large proportion of PP market. In recent years, with the increasing of PP production, $\mathrm{PP}$ begins to enter the field of engineering plastic. Because its strength is not strong enough, pristine PP can not be used directly as engineering plastics.

In order to obtain high performance of PP materials, the pristine PP should be modified. With strong mechanical strength and ultralow density as well as larger aspect ratio, a small amount of carbon nanotubes (CNTs) can improve the mechanical strength of the polymer [1-4]. In recent years, an enormous research interest has been focused on CNTs/polymer composites [5-11]. As a kind of nanomaterial, CNT is very easy to agglomerate, which is bound to affect the mechanical strength of nanocomposites.

High strength properties of CNTs/polymer composites are achieved only in the case of an existing interaction between components and the dispersion of CNTs within the matrix. Grady found that functionalized or grafted CNTs could promote CNTs dispersion [12]. Araujo et al. used the methods of in situ polymerization of monomers on the nanotubes to producing nanocomposite material with evenly dispersed CNTs [13]. Ritter et al. found that electron irradiation could improve the mechanisms of microhardness of the CNTs/PP [14]. Ghoshal et al. used the approaches of combination of solution processing and melt blending and they found that dispersion quality was notably improved in the solution processed master batch based samples $[15,16]$.

However, it should be noted that the melt mixing is the most convenient and environmentally friendly method for preparing CNTs/polymer nanocomposites and is being used more and more in industry [17]. In this work, the $\mathrm{PP} / \mathrm{MWNT}$ nanocomposites are prepared by melt extrusion. The mechanical strength of PP/MWNTs nanocomposites is tested. And then the PP nanocomposites with hydroxylmodified multiwalled carbon nanotubes (HO-MWNTs) are prepared. The morphology of PP nanocomposites is observed by SEM.

\section{Experimental}

2.1. Materials. PP resin (trade mark BJ550, Samsung Total) is used as basal material. MWNTs and HO-MWNTs are offered by Xian Feng Nano Company.

2.2. Preparation of PP/CNTs Nanocomposites. First, MWNTs, HO-MWNTs, and PP were dried in a vacuum oven for $12 \mathrm{~h}$ at $80^{\circ} \mathrm{C}$ to reduce volatiles. According to the formula as shown in Table 1, the composites were premixed for 5 minutes at 
TABLE 1: Formulations of the nanocomposites.

\begin{tabular}{lccc}
\hline $\begin{array}{l}\text { Sample } \\
\text { number }\end{array}$ & PP (wt.\%) & $\begin{array}{c}\text { MWNTs } \\
\text { (wt.\%) }\end{array}$ & $\begin{array}{c}\text { HO-MWNTs } \\
\text { (wt.\%) }\end{array}$ \\
\hline 1 & 100 & 0 & 0 \\
2 & 99.6 & 0.4 & 0 \\
3 & 99.4 & 0.6 & 0 \\
4 & 99.2 & 0.8 & 0 \\
5 & 99 & 1 & 0 \\
\hline 6 & 99 & 0 & 1 \\
\hline
\end{tabular}

stirring speed of $2000 \mathrm{rpm}$ using high speed mixer (SHR10). Then, the mixture of nanocomposite was manufactured by twin screw extruder (CTE35). The temperature range of the extruder was from $155^{\circ} \mathrm{C}$ to $195^{\circ} \mathrm{C}$ and the shear rate was $40 \mathrm{rpm}$. Finally, put the mixture of the nanocomposite into the injection molding machine (FT-110) and mold it into standard spline.

2.3. Testing. Tensile tests were carried out using universal testing machine (WDT-W) at the speed of $50 \mathrm{~mm} / \mathrm{min}$ according to the national standard of China GB/T 1040-1992. The dimension of the dumbbell shaped samples is $10 \mathrm{~mm}$ $\times 4 \mathrm{~mm}$ in the narrow part. And the impact strength tests were carried out using simple beam impact tester (JC-5) according to the national standard of China GB/T 1843-2008. The dimension of the sample is $10 \mathrm{~mm} \times 4 \mathrm{~mm}$. For all the mechanical tests, five samples were tested and the standard deviations were calculated.

Impact-fractured surfaces of the PP/MWNT nanocomposite containing $1 \mathrm{wt} \% \mathrm{MWNT}$ and HO-MWNTs were investigated by SEM using Zeiss evol8 model.

\section{Results and Discussion}

3.1. Mechanical Property of PP/MWNTs Nanocomposites. The tensile strength of nanocomposites with various MWNTs contents is shown in Figure 1. It can be seen that, with the increase of concentration of MWNTs, the tensile strength of the nanocomposite appears to increase as compared to the pristine PP. Tensile strength for the blends increases with increasing of MWNTs, on the one hand due to the relatively high strength of carbon tube and on the other hand due to ultra high aspect ratio of carbon tube. When subjected to an external force, the load of external force can be dispersed along the length direction of the carbon tube.

In the case of elongation at break, it is decreased gradually with the increase amount of MWNTs as shown in Figure 2. Elongation at break is depending on the flexibility of the molecular chain. The conformation change of polymer chain is restricted by the MWNTs, which leads to the decrease of the elongation at break.

Bending strength and impact strength are an important index of engineering materials. As shown in Figure 3, the bending strength of the nanocomposites increases gradually with the increase amount of MWNTs.

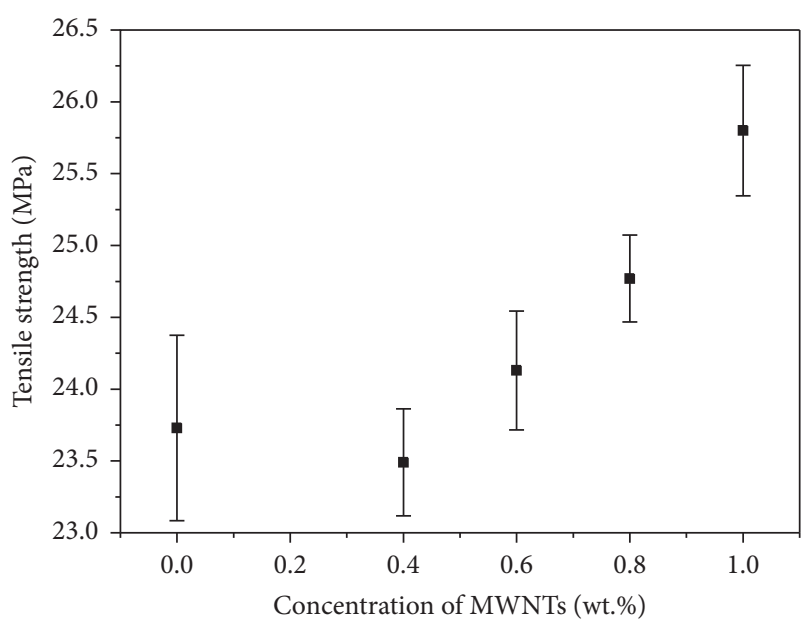

Figure 1: Tensile strength of PP/MWNTs nanocomposites.

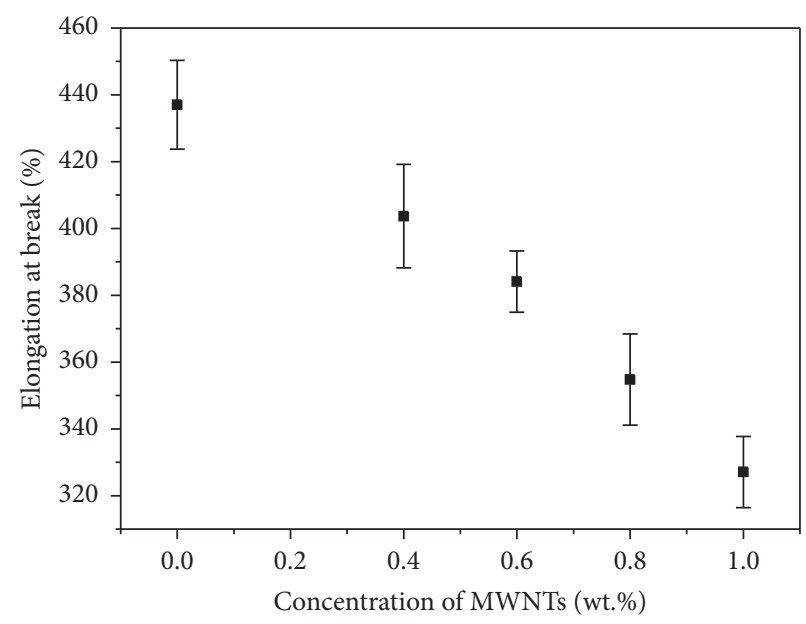

FIgURE 2: Elongation at break of PP/MWNTs nanocomposites.

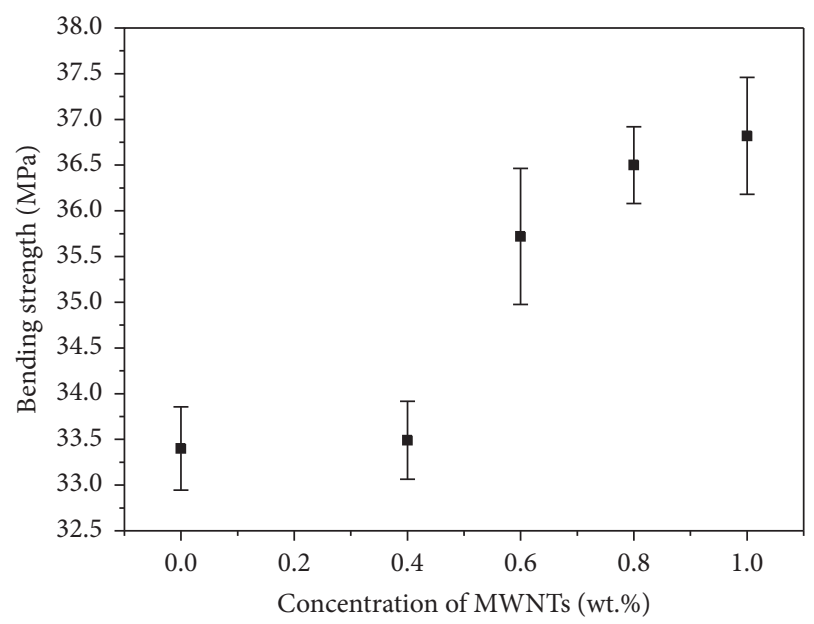

FIGURE 3: Bending strength of PP/MWNTs nanocomposites. 


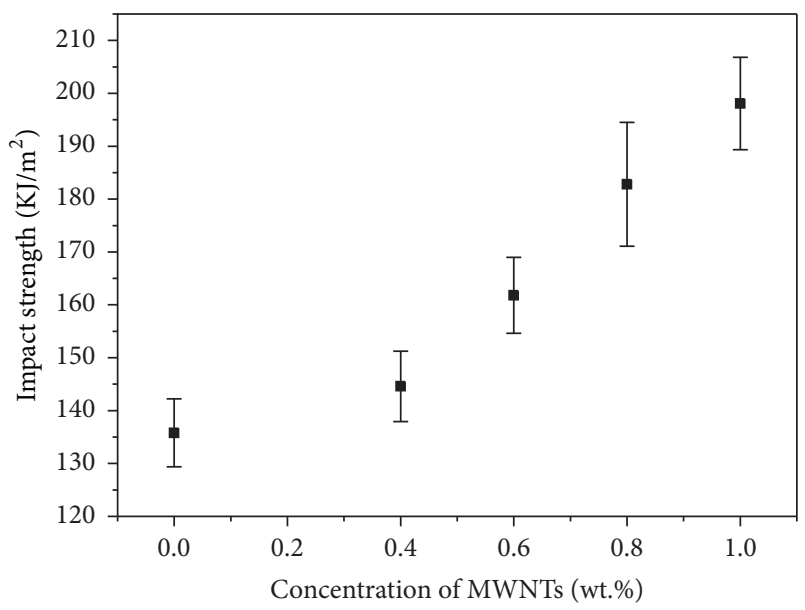

FIGURE 4: Impact strength of PP/MWNTs nanocomposites.

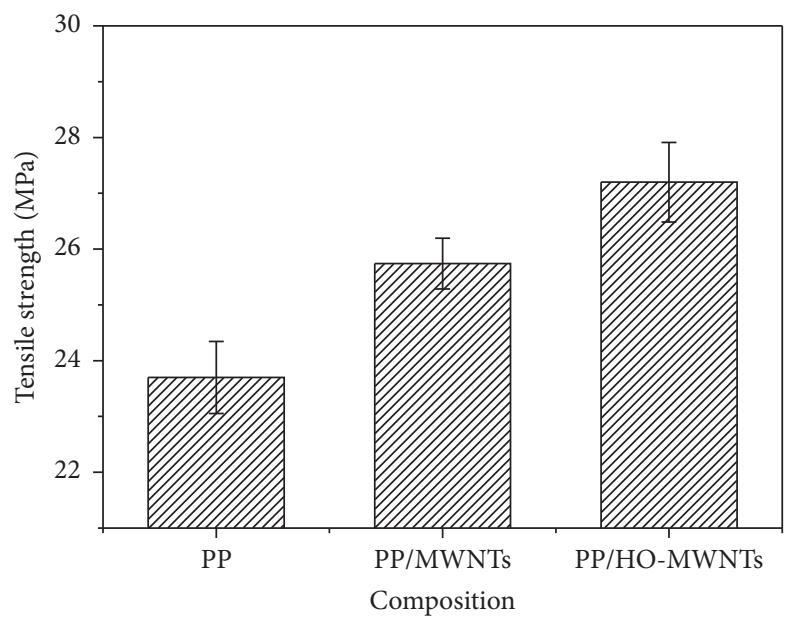

FIGURE 5: Tensile strength of nanocomposites.

The impact strength is characterized by the destruction of the material's ability to resist damage. One of the most important characteristics of engineering plastics is high performance of impact strength. The performance of impact strength with the increase of MWNTs content is shown in Figure 4. With the increase of MWNTs content, the impact strength of the composite increased gradually. It is hypothesized that MWNTs could effectively dissipate the impact energy from the polymer matrix to the MWNTs.

3.2. Influence of HO-MWNTs on the Performance of PP. As shown in Figures 5-8, we find that adding the same amount of HO-MWNTs can improve the mechanical strength of nanocomposite compared with MWNTs. To elucidate the dispersion of MWNTs and HO-MWNTs, an analysis of nanocomposites microphotographs has been investigated in detail. Figures 9-10 show the SEM image of PP/MWNTs and $\mathrm{PP} / \mathrm{HO}-\mathrm{MWNTs}$. AS shown in Figure 9, most of MWNTs are likely to get together. The gathering of MWNTs is very easy to form defects, which is the stress concentration point in the

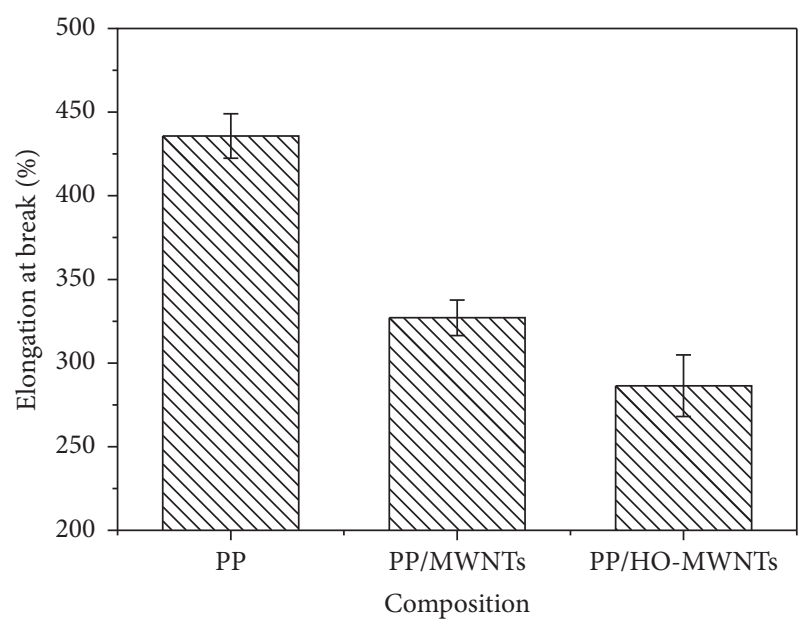

FIGURE 6: Elongation at break of nanocomposites.

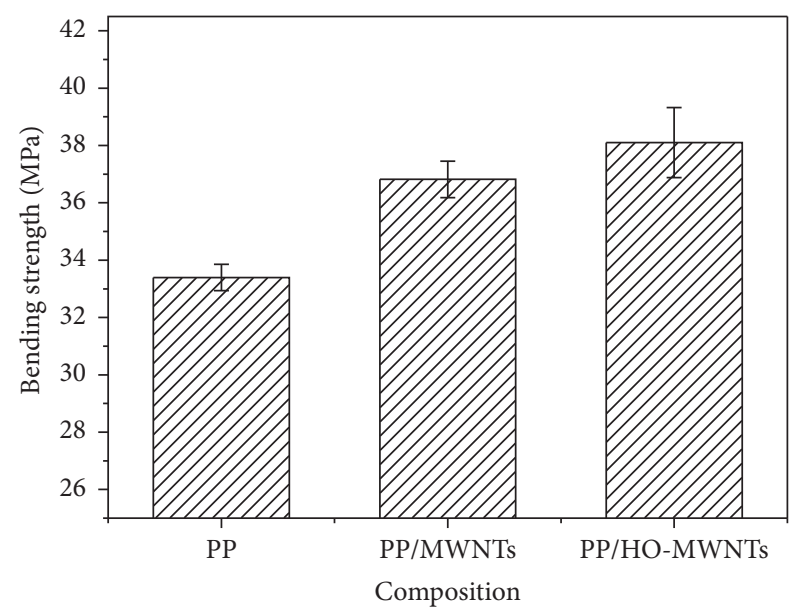

FiguRE 7: Bending strength of nanocomposites.

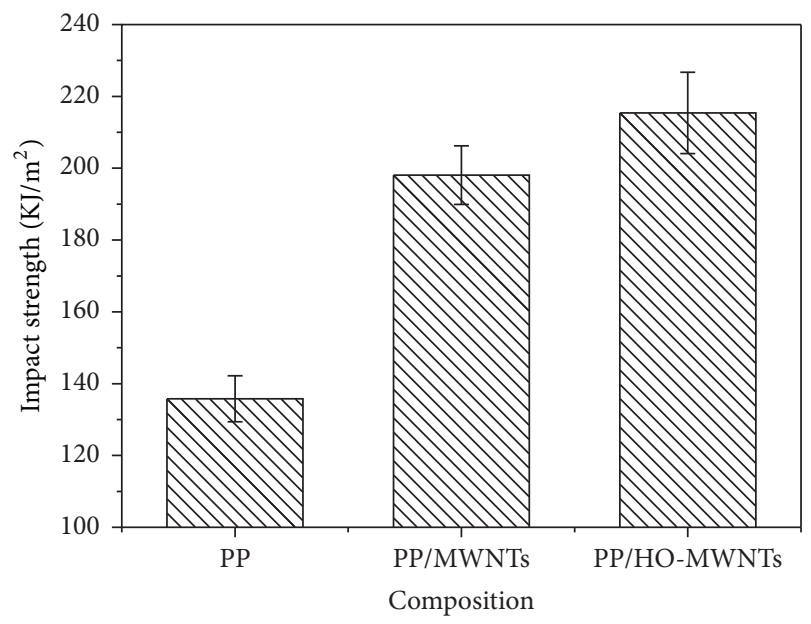

FIGURE 8: Impact strength of nanocomposites. 


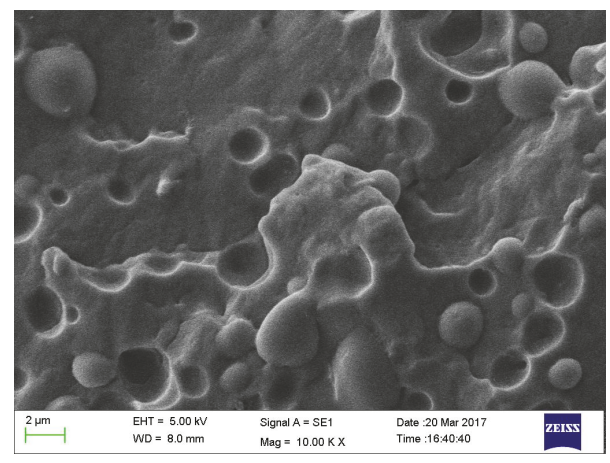

FIgURE 9: SEM microphotograph of the PP/MWNTs nanocomposites.

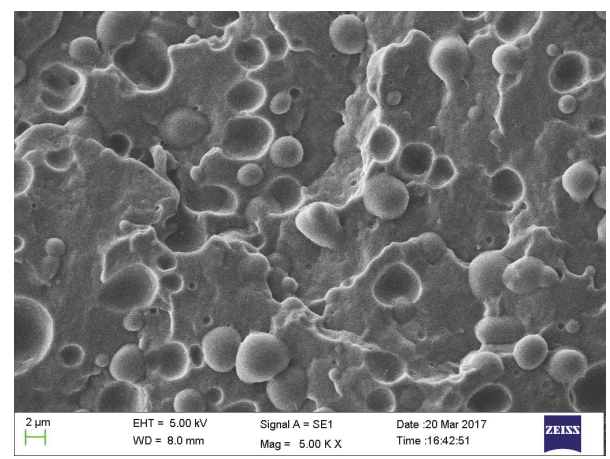

Figure 10: SEM microphotograph of the PP/HO-MWNTs nanocomposites.

case of external forces. After sodium hydroxide being modified, there are a lot of hydroxyl groups on the HO-MWNTs. These hydroxyl groups could prevent the carbon tube from poly and increase the dispersion of carbon nanotubes in the composite material.

\section{Conclusion}

Nanocomposites based on PP/MWNTs and PP/HO-MWNTs were prepared with a twin screw extruder. The nanocomposites exhibited not only improved tensile strength but also increased bending strength and impact strength. However, the elongation at break decreased with the increasing content of MWNTs. The results showed that the HO-MWNTs can further improve the tensile strength, bending strength, and impact strength of the material compared with MWNTs. The structure and morphology of the prepared samples were examined through SEM. Compared with MWNTs, HOMWNTs could get better dispersion in nanocomposites.

\section{Conflicts of Interest}

The author declares that they have no conflicts of interest.

\section{Acknowledgments}

Funding for this work was provided by the Jiangsu Provincial Natural Science Research Project (16KJB430033) and Youth Foundation of NIIT (QK13-01-01).

\section{References}

[1] P.-C. Ma, N. A. Siddiqui, G. Marom, and J.-K. Kim, “Dispersion and functionalization of carbon nanotubes for polymer-based nanocomposites: a review," Composites A: Applied Science and Manufacturing, vol. 41, no. 10, pp. 1345-1367, 2010.

[2] D. Qian, G. J. Wagner, W. K. Liu, M. Yu, and R. S. Ruoff, "Mechanics of carbon nanotubes," Applied Mechanics Reviews, vol. 55, no. 6, pp. 495-533, 2002.

[3] M. Razavi-Nouri, M. Ghorbanzadeh-Ahangari, A. Fereidoon, and M. Jahanshahi, "Effect of carbon nanotubes content on crystallization kinetics and morphology of polypropylene," Polymer Testing, vol. 28, no. 1, pp. 46-52, 2009.

[4] N. Montinaro and A. Pantano, "Parameters influencing the stiffness of composites reinforced by carbon nanotubes - a numerical-analytical approach," Composite Structures, vol. 109, no. 1, pp. 246-252, 2014.

[5] L. Valentini, J. Biagiotti, J. M. Kenny, and S. Santucci, "Effects of single-walled carbon nanotubes on the crystallization behavior of polypropylene," Journal of Applied Polymer Science, vol. 87, no. 4, pp. 708-713, 2003.

[6] J. Yang, Z. Zhang, K. Friedrich, and A. K. Schlarb, "Creep resistant polymer nanocomposites reinforced with multiwalled carbon nanotubes," Macromolecular Rapid Communications, vol. 28, pp. 955-961, 2007.

[7] S. Kumar, H. Doshi, M. Srinivasarao, J. O. Park, and D. A. Schiraldi, "Fibers from polypropylene/nano carbon fiber composites," Polymer, vol. 43, no. 5, pp. 1701-1703, 2002.

[8] A. R. Bhattacharyyaa, T. V. Sreekumara, T. Liua et al., "Crystallization and orientation studies in polypropylene/single wall carbon nanotube composite," Polymer, vol. 44, no. 8, pp. 23732377, 2003.

[9] H. Zhang and Z. Zhang, "Impact behaviour of polypropylene filled with multi-walled carbon nanotubes," European Polymer Journal, vol. 43, no. 8, pp. 3197-3207, 2007.

[10] K. Prashantha, J. Soulestin, M. F. Lacrampe, P. Krawczak, G. Dupin, and M. Claes, "Masterbatch-based multi-walled carbon nanotube filled polypropylene nanocomposites: assessment of rheological and mechanical properties," Composites Science and Technology, vol. 69, no. 11-12, pp. 1756-1763, 2009.

[11] M. C. Hsiao, S. H. Liao, Y. F. Lin et al., "Polypropylene-grafted multi-walled carbon nanotube reinforced polypropylene composite bipolar plates in polymer electrolyte membrane fuel cells," vol. 4, no. 2, pp. 543-550, 2011.

[12] B. P. Grady, Carbon Nanotube-Polymer Composites: Manufacture, Properties and Applications, Wiley, New York, NY, USA, 2011.

[13] R. S. Araujo, R. J. B. Oliveira, and M. D. F. V. Marques, "Preparation of nanocomposites of polypropylene with carbon nanotubes via masterbatches produced by in situ polymerization and by melt extrusion," Macromolecular Reaction Engineering, vol. 8, no. 11, pp. 747-754, 2014.

[14] U. Ritter, P. Scharff, O. P. Dmytrenko et al., "Strength improvement of iPP/MWCNT nanocomposites," Polymer Composits, vol. 31, no. 1, pp. 179-184, 2010. 
[15] S. Ghoshal, P. H. Wang, P. Gulgunje, N. Verghese, and S. Kumar, "High impact strength polypropylene containing carbon nanotubes," Polymer, vol. 100, pp. 259-274, 2016.

[16] P. H. Wang, S. Ghoshal, P. Gulgunje, N. Verghese, and S. Kumar, "Polypropylene nanocomposites with polymer coated multiwall carbon nanotubes," Polymer, vol. 100, pp. 244-258, 2016.

[17] S. R. Katti, B. K. Sridhara, L. Krishnamurthy, and G. L. Shekar, "Mechanical behaviour of MWCNT filled polypropylene thermoplastic composites," Indian Journal of Advances in Chemical Science, vol. 2, pp. 6-8, 2014. 

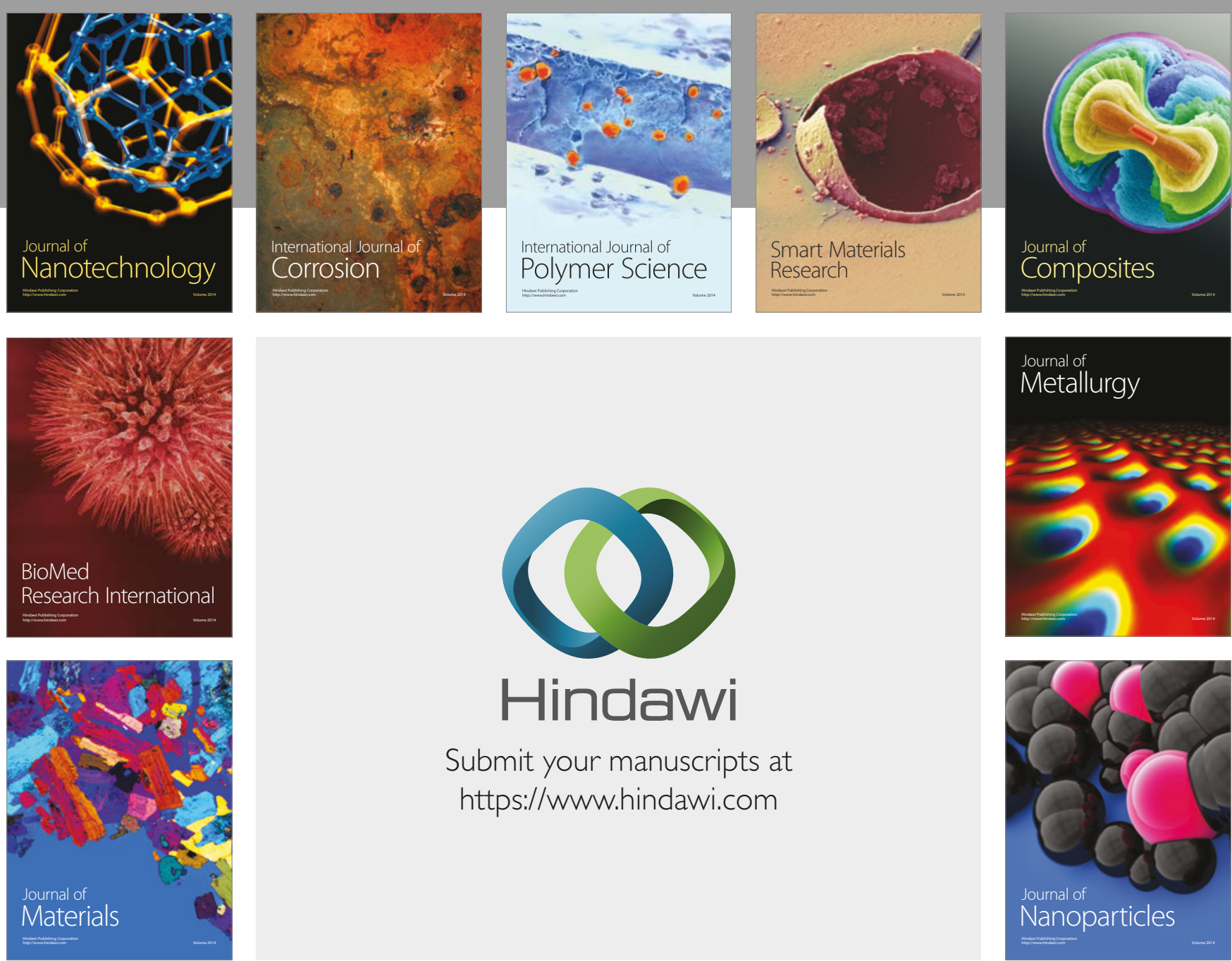

\section{Hindawi}

Submit your manuscripts at

https://www.hindawi.com
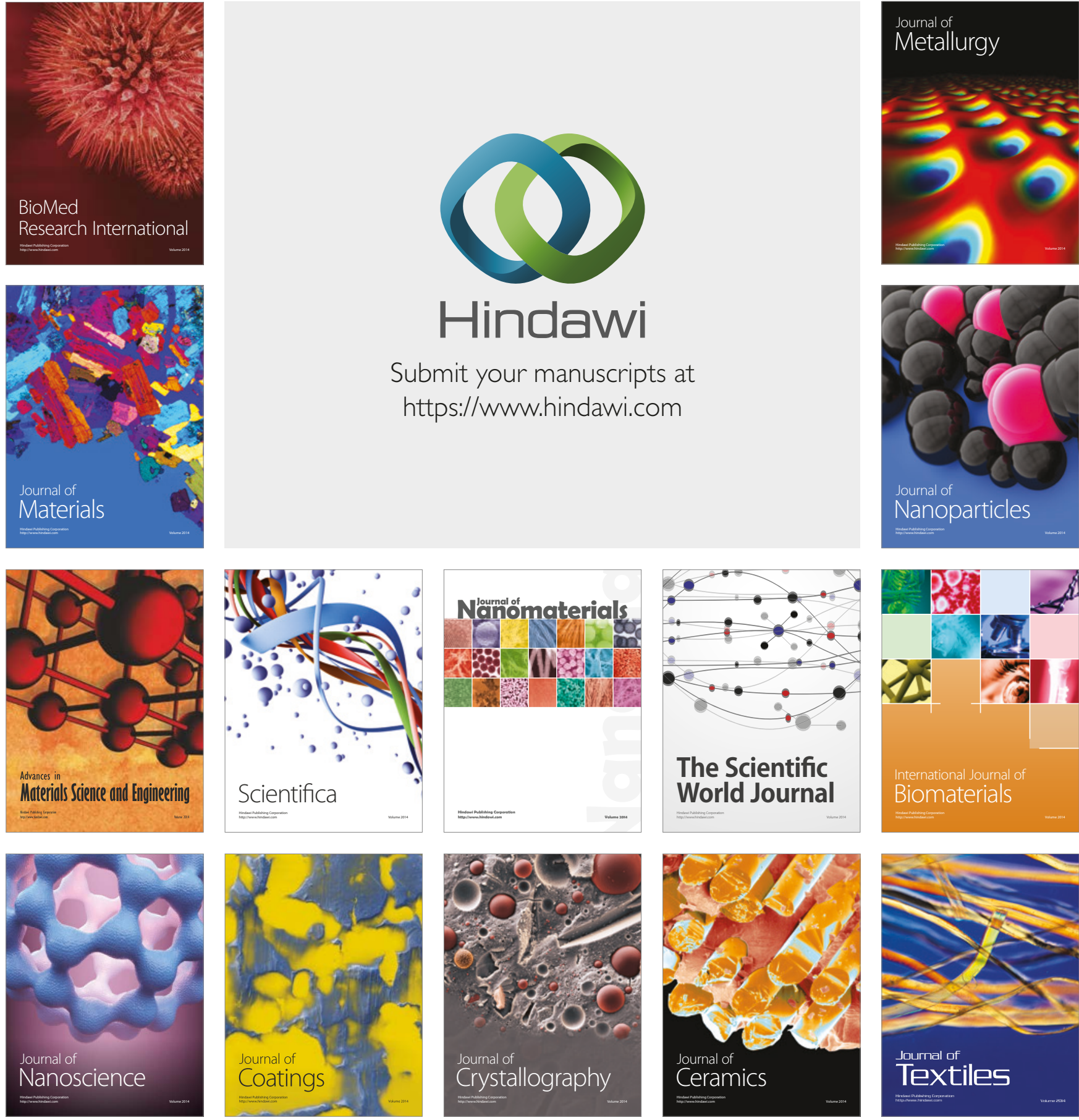

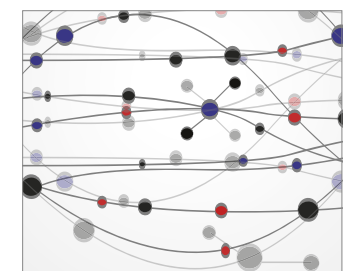

The Scientific World Journal
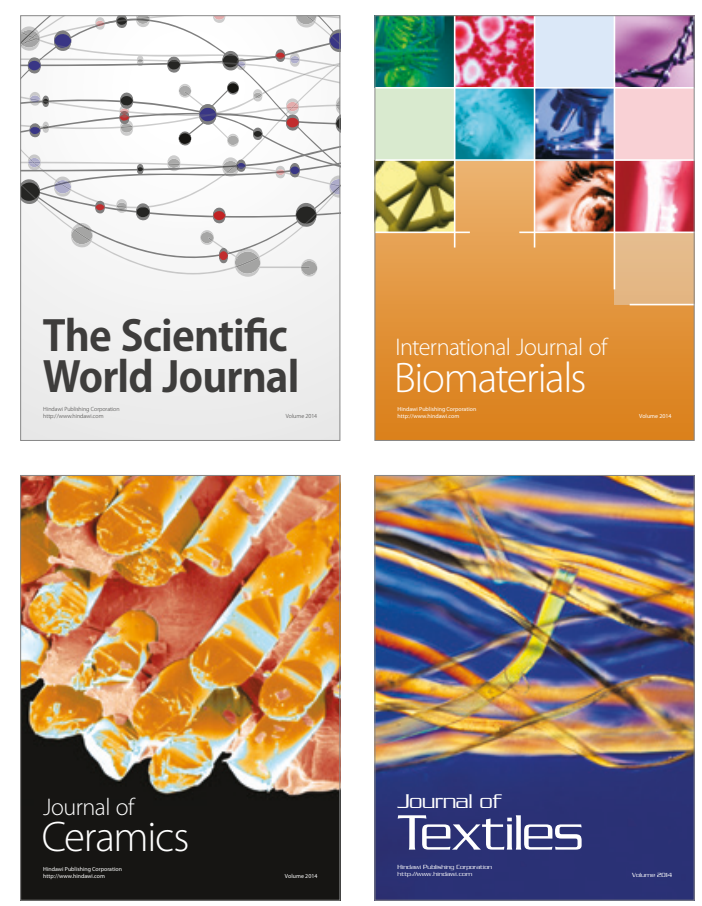